\title{
Avaliação do desempenho dos revestimentos WC-CoCr por HVOF e cromo duro eletrodepositado para aplicação em pás de misturadores para cerâmica vermelha
}

\author{
Bruno Nicoladelli Netto \\ Reginaldo Rosso Marcello ${ }^{2}$ \\ Richard de Medeiros Castro ${ }^{3}$ (D) \\ Elvys Isaías Mercado Curi ${ }^{4}$ \\ Luiz Carlos de Cesaro Cavaler ${ }^{5}$
}

\section{Resumo}

Devido à característica abrasiva da argila utilizada na fabricação de tijolos, telhas e blocos estruturais, as pás dos misturadoras sofrem um desgaste abrasivo severo, que acarreta numa baixa eficiência da mistura e produtos de baixa qualidade. Geralmente essas pás são fabricadas em ferro fundido nodular, um material de baixa dureza. A crescente demanda da indústria cerâmica por menores custos e maior produtividade, estão entre as principais justificativas para a melhoria do desempenho desses misturadores. Portanto, este trabalho tem por objetivo avaliar a performance de revestimentos metálicos, fabricados por cromo duro eletrodepositado e pelo processo de aspersão térmica - tipo High Velocity Oxy-Fuel (HVOF), utilizando a liga WC-CoCr. Neste trabalho foi avaliada a resistência ao desgaste abrasivo dos revestimentos, pelo ensaio padrão ASTM G65 e de aplicação industrial. Embora a liga de WC tenha a dureza maior comparada ao cromo duro, o

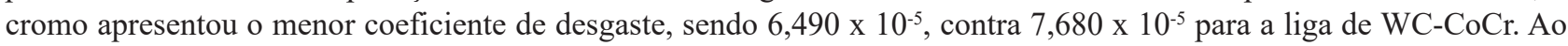
final, percebeu-se a viabilidade de aplicação apenas para o cromo duro, devido ao custo da liga de carbeto de tungstênio.

Palavras-chave: Misturadores; Ferro fundido nodular; Desgaste; Cromo duro; WC-CoCr.

\section{Evaluation of performance of WC-CoCr coatings with HVOF and hard chrome for application in clay mixing machine}

\begin{abstract}
Due to the abrasive characteristic of the clay used in the manufacture of bricks, tiles, and structural blocks, the blades of mixers suffer severe abrasive wear, which results in low mixing efficiency and low-quality products. These blades are made of nodular cast iron, a low-hardness alloy. The growing demand from the ceramic industry for lower costs and higher productivity are among the main reasons for improving the performance of these mixers. Therefore, this work aims to evaluate the performance of metallic coatings, manufactured by electrodeposited hard chromium and by the thermal spraying process - type High-Velocity Oxy-Fuel (HVOF), using the WC-CoCr alloy. In this research, it was evaluated the resistance to abrasive wear of the coatings, by the standard test ASTM G65 and of industrial application. Although the WC alloy has the highest hardness compared to hard chromium, the chromium coating showed the lowest wear coefficient, $6,490 \times 10^{-5}$, and 7,680 $\times 10^{-5}$ for the WC-CoCr alloy. With the study, it was realized the feasibility of application only of hard chromium, due to the cost of the tungsten carbide alloy.
\end{abstract}

Keywords: Mixers; Nodular cast iron; Wear; Hard Chrome; WC-CoCr.

\section{Introdução}

O uso de tijolos, telhas, tavelas e revestimentos cerâmicos, são os materiais mais usados na construção de casas e apartamentos para fazer a vedação estrutural. O processo de fabricação desses produtos é complexo, pois exige uma preparação adequada da matéria prima, extrusão, secagem e queima. Desta forma, o equipamento em estudo, apresentado

${ }^{1-5}$ Engenharia Mecânica, Centro Universitário - UNISATC, Criciúma, SC, Brasil.

*Autor correspondente: richard.castro@satc.edu.br

2176-1523 (C) 2021. Netto et al. Publicado pela ABM. Este é um artigo publicado em acesso aberto (Open Access) sob a licença Creative Commons Attribution, que permite uso, distribuição e reprodução em qualquer meio, sem restrições desde que o trabalho original seja corretamente citado. 
na Figura 1, se inclui na linha de produção antecedendo à extrusão. Sua principal função é misturar os diversos tipos de argila, proporcionando uma homogeneização da massa formada. A peça principal do estudo são as pás que fazem a mistura da matéria prima.

Tradicionalmente, as pás dos misturadores são revestidas por camadas duras depositada por soldagem ou fabricadas de ferro fundido nodular. $\mathrm{O}$ baixo custo destas peças, justificam o uso de um material inferior, tanto para o processo de soldagem quanto de fundição. A escolha destes materiais, interferem diretamente na durabilidade dessas peças, assim prejudicando o desempenho da máquina, criando intervalos curtos de manutenção ou até a substituição destas. Esse processo se dá em função da abrasividade da matéria prima (argila) utilizada na fabricação de tijolos ou telhas. Em sua composição química encontrasse a sílica $\left(\mathrm{SiO}_{2}\right)$, um componentes extremamente abrasivo. Quando este material abrasivo entra em contato direto com peças metálicas, acarreta num desgaste acentuado.

O desgaste de peças metálicas é um fenômeno muito comum, principalmente na indústria cerâmica e de mineração. Atualmente, o desgaste é considerado uma falha quando atinge níveis críticos de perda de forma e material em um componente, afetando o processo de fabricação [1-3]. No entanto, a performance das máquinas, assim com um aumento de vida útil dos componentes, visa reduzir substancialmente o custo das indústrias. Neste contexto, o desgaste abrasivo é o principal causador de reposição em componentes mecânicos. Estima-se que a perda por desgaste em um país desenvolvido é de 1 a $6 \%$ do PIB, sendo que $20 \%$ das perdas poderiam ser evitadas com estudos voltados para a área de tribologia nas indústrias [4]. De acordo com a NATREB [5], esse problema não envolve apenas custos por peças de reposição, mas também em perdas de produção, custo de depreciação dos equipamentos e de oportunidades de negócios [5].

A adição de rejeitos na matéria prima, como pedaços de tijolos, pedras e areias melhoram na qualidade do produto, porém, essa adição acentua ainda mais o desgaste das pás, devido a elevada dureza que estes elementos já vitrificados possuem, assim interferindo no sistema tribológico [6]. Um dos abrasivo mais comum encontrados na composição da matéria prima cerâmica é a sílica, normalmente com uma dureza média de $800 \mathrm{HV}$.

Algumas pesquisas mostram que obter uma boa resistência à abrasão das superfícies, é necessário aumentar a dureza destas, sendo por processos tradicionais de tratamento térmico, ou usando técnicas de deposição de revestimentos na superfície $[7,8]$. Por meio destas técnicas, podem se obter carbonetos precipitados na matriz com tamanhos e morfologias definidas. Dentre os principais processos e ligas contra o desgaste abrasivo, destacam-se: o cromo eletrolítico (1100-950 HV), aço carbonetado (900 HV), aço nitretado (1250-900 HV) e carboneto de tungstênio (1200-1400 HV) [9]. Contudo, para concluir qual propriedade mais atua no processo, é necessário analisar a aplicação real [10]. Também é importante considerar a rugosidade da superfície, pois superfícies muito lisas tendem a apresentar maiores coeficientes de atrito, quando comparado à superfície com maior rugosidade $[11,12]$.

O objetivo deste estudo é identificar os principais elementos abrasivos contidos nas argilas de duas diferentes indústrias cerâmicas, e assim, avaliar de forma comparativa, o desgaste de revestimentos metálicos que foram produzidos por eletrodeposição de cromo duro e aspersão térmica - HVOF. O intuito final com essa deposição é evitar a substituição do material base. Todos os ensaios são relacionados ao material base sem revestimento, pois espera-se aumentar a durabilidade para viabilizar os custos de fabricação e aplicação.

\section{Procedimento Experimental}

\subsection{Análise Mineralógica e de Composição Química da Argila}

A análise da matéria prima foi realizada com duas argilas de diferentes indústrias. A análise foi realizada num difratômetro de Raio X (DRX) modelo XRD-6100 da SHIMADZU. Os parâmetros para a realização do teste, foram: passo de $0,02^{\circ}$, tempo de passo de 0,6 segundos e intervalo de medida, em $2 \theta$ de $4^{\circ}$ a $70^{\circ}$. Na interpretação dos resultados foi utilizado o banco de dados do próprio difratômetro.

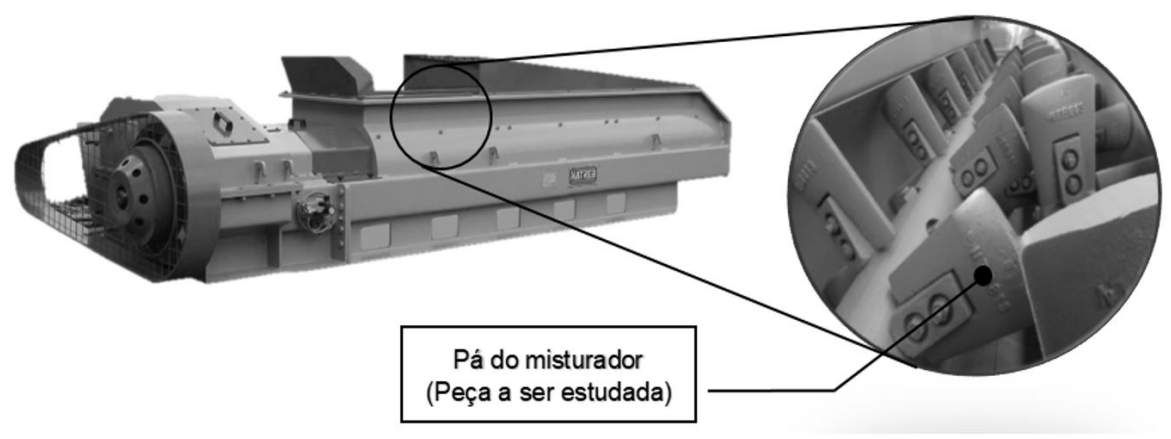

Figura 1. Misturador MTR-4B [1]. 
A composição química foi realizada por espectrometria de fluorescência de raio-X (FRX) por energia dispersiva (EDXRF).

\subsection{Preparação dos Corpos de Prova de Desgaste}

Para os ensaios em laboratório conforme ASTM - G65 [13], foram produzidos três corpos de prova (CP) para cada revestimento duro e três corpos de provas para o material original das pás, conforme Tabela 1 .

Como os ensaios também foram realizados em condições reais de aplicação (teste de aplicação industrial), foi necessário adquirir 6 pás originais, sendo 2 pás revestidas com cromo duro, 2 com WC-CoCr e 2 pás originais sem revestimento de ferro fundido nodular (FFN). Um conjunto de 3 unidades cada, foi aplicado para cada tipo de argila em estudo. $\mathrm{O}$ tempo de teste para todas as pás foi de 43 dias, com uma operação de 9 horas por dia, durante 6 dias por semana. Nos testes utilizou-se as duas argilas citadas, mantendo-se estas das mesma jazida.

\subsection{Preparação da superfície}

A preparação das superfícies do revestimento WC-CoCr foi realizada a partir do jateamento com óxido de alumínio $\left(\mathrm{Al}_{2} \mathrm{O}_{3}\right)$ de forma angular a $90^{\circ}$ com partículas de 120 mesh. Esse jateamento teve como objetivo, remover as impurezas da superfície, bem como obter uma rugosidade

Tabela 1. Identificação dos corpos de provas

\begin{tabular}{ccl}
\hline Denominação & Quantidade & \multicolumn{1}{c}{ Material/Liga } \\
\hline CP 1 & 3 & Ferro Fundido Nodular (FFN) \\
CP 2 & 3 & Cromo Duro (Cr) \\
CP 3 & 3 & WC-CoCr $(\mathrm{Wc})$ \\
\hline
\end{tabular}

que proporcione um melhor ancoramento mecânico do revestimento ao substrato.

\subsection{Aplicação dos revestimentos metálicos}

O cromo duro catalisado é fabricado pelo processo eletrolítico de corrente contínua, em uma solução à base de cromo, ou seja, as peças são imersas em um banho de cromo, dessa forma, este banho é composto de anidrido crômico $\left(\mathrm{Cr}_{2} \mathrm{O}_{3}\right)$ dissolvido em água $\left(\mathrm{H}_{2} \mathrm{O}\right)$ e passa a ser ácido crômico. Na solução é adicionado o catalizador e ácido sulfúrico $\left(\mathrm{H}_{2} \mathrm{SO}_{4}\right)$. Por sua vez, a temperatura e corrente de aplicação não podem ser divulgadas pelo sigilo de aplicação, porém em características gerais à densidade da corrente é de 31 a $62 \mathrm{~A} / \mathrm{cm}^{2}$ e temperatura de 52 a $63^{\circ} \mathrm{C}$. A espessura da camada aplicada na superfície foi de $0,20 \mathrm{~mm}$.

Para a aplicação do carbeto de tungstênio, a metalização é realizada pelo processo de HVOF, utilizou-se o equipamento DJ2700 da marca Oerlikon Metco. Os principais parâmetros são apresentados na Tabela 2.

Após a aplicação dos revestimentos a medição da rugosidade foi realizada por um rugosímetro digital TR 100 Surface Roughness Tester, fabricado por Time Group INC. As medições seguiram a seleção do cut-off $\left(\lambda_{c}\right)$ inicial, selecionado $\lambda_{3}$ com variações de até $2,5 \mathrm{~mm}$ e o parâmetro Ra de medição.

\subsection{Ensaio de desgaste - ASTM G65}

A taxa de desgaste foi obtida utilizando-se o ensaio de desgaste por roda de borracha e areia (procedimento A) da norma ASTM G65-16 Figura 2.

Os resultados foram caracterizados pela perda de volume das amostras com a densidade específica de cada material. Este ensaio simula à abrasão à baixa tensão, onde o

Tabela 2. Parâmetros utilizados no processo de aspersão térmica HVOF

\begin{tabular}{ccc}
\hline Descrição & Valores & Descrição \\
\hline Taxa de alimentação & $80-90 \mathrm{~g} / \mathrm{min}$ & Vazão de nitrogênio \\
Pressão de oxigênio & $136 \pm 5 \mathrm{PSI}$ & Distância da pistola ao CP \\
Vazão de oxigênio & $2000 \mathrm{scfh}$ & Tamanho do canhão \\
Pressão de combustível & $120 \pm 10 \mathrm{PSI}$ & Pressão de ar comprimido \\
Vazão de combustível & $6 \mathrm{gph}$ & Vel. desloc. da pistola \\
Pressão de nitrogênio & $70 \mathrm{PSI}$ & Camada esperada \\
\hline
\end{tabular}

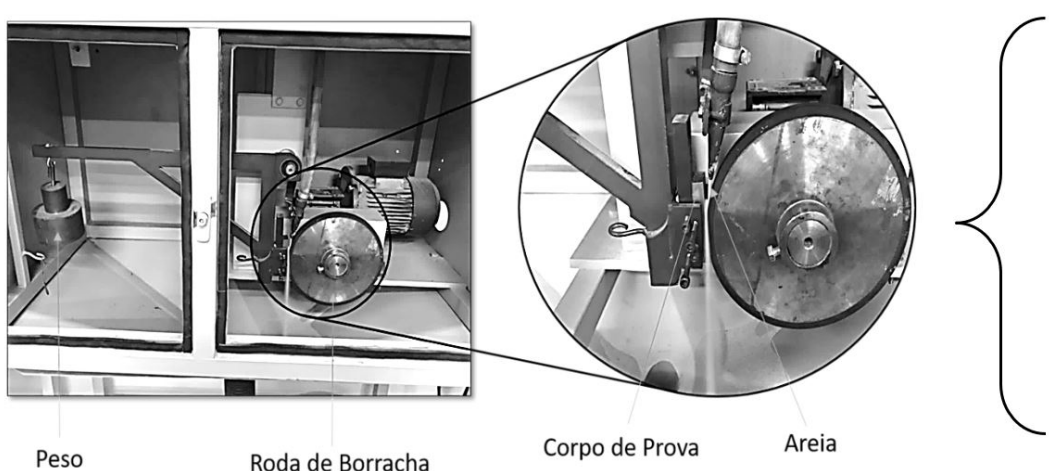

Figura 2. Detalhe do ensaio de desgaste ASTM G65 e parâmetros de teste.

\begin{tabular}{c|c}
\hline Parâmetros & Valores \\
\hline Vazão de areia & $325 \mathrm{~g} / \mathrm{min}$ \\
Carga aplicada & $130 \mathrm{~N}$ \\
Tempo total do ensaio & $30 \mathrm{~min}$ \\
Granulometria da areia & $50 \mathrm{mesh}$ \\
Rotação da roda & $200 \mathrm{rpm}$ \\
Diâmetro da roda & $228,4 \mathrm{~mm}$ \\
Tempo total por peça & $30 \mathrm{~min}$ \\
\hline
\end{tabular}

Tecnol Metal Mater Min. 2021;18:e1984 
fluxo de areia é responsável por simular o desgaste abrasivo na configuração a três corpos sobre a superfície das amostras, conforme ilustrado na Figura 2. Cada ensaio foi realizado num tempo total de 30 minutos, sendo executado uma parada a cada 6 minutos, a fim de obter a constante $K_{a}$ de desgaste.

Para a quantificação do desgaste, utilizou-se uma balança de precisão com capacidade de $500 \mathrm{~g}$ e resolução de 0,01 g. Em seguida o desgaste foi convertido em volume perdido, por meio da massa específica de cada material, sendo $4,25 \mathrm{~g} / \mathrm{cm}^{3}$ para o ferro fundido nodular(FFN), $7,10 \mathrm{~g} / \mathrm{cm}^{3}$ para o cromo duro $(\mathrm{Cr}) \mathrm{e}$ $15,63 \mathrm{~g} / \mathrm{cm}^{3}$ para o carbeto de tungstênio (Wc). Com o resultado da perda de volume é possivel aplicar este valor na equação de Achard [14], que avalia a taxa de desgaste, relacionando o volume perdido acumulado por unidade de distância percorrida com a resistência ao desgaste através da Equação 1.

$$
K_{a}=\frac{Q \cdot H}{F_{n} \cdot L}
$$

Em que, $\mathrm{Q}=$ Volume removido de material $\left(\mathrm{mm}^{3}\right) ; \mathrm{H}=$ Dureza do material mais mole $\left(\mathrm{N} / \mathrm{m}^{2}\right) ; \mathrm{F}_{\mathrm{n}}=$ Carga nominal aplicada $(\mathrm{N}) ; \mathrm{L}=$ Deslizamento linear $(\mathrm{m})$

\subsection{Análise de microdureza e microestrutura}

A microestrutura das amostras foi analisada por microscopia ótica (MO). A observação das microestruturas foi realizada em microscópio óptico Olympus BX5 1M onde pode-se observar o substrato e o revestimento. Para verificar a base do substrato e também se os revestimentos prejudicaram a superfície do substrato, foi feito o ataque em nital $2 \%$ por 2 segundos em cada peça. Os testes de dureza Vickers foram realizados em um microdurômetro Shimadzu HMV-2 TADW de acordo com a ISO 14577-1. Uma carga de $0,50 \mathrm{~N}$ foi aplicada, pelo tempo de $8 \mathrm{~s}$, classificando a escala $\mathrm{HV}_{0,05}$. Seguindo de 8 endentações realizadas verticalmente na secção transversal de cada amostra (em linha), sendo 3 endentações no revestimento e as demais realizados no substrato.

\section{Resultados e análises}

\subsection{Análise de microdureza e de microestrutura}

De acordo com Davim [15] o aumento da dureza nas peças que sofrem desgaste por abrasão a baixa tensão já possibilita um aumento em sua vida útil [15]. Na Tabela 3 é possível verificar os valores médios de microdureza para ambos revestimentos e substrato.

A Figura 3 apresenta-se o perfil de dureza gerado a partir da superfície até o núcleo do substrato para cada revestimento.

A dureza encontrada dos revestimentos está de acordo com a literatura, com uma dureza média de $1100 \mathrm{HV}$ para o cromo duro e de $1500 \mathrm{HV}$ para o carboneto de tungstênio. Observando apenas a dureza da superfície, o Wc deveria apresentar uma taxa de desgaste menor que o cromo duro, porém foi obtido menores taxas desgaste para este revestimento. Portanto, é necessário verificar outros fatores, como a granulometria dos grãos e às camadas revestidas, com uma análise das micrografias, como é apresentada na Figura 4.

Observa-se que a microestrutura depositada por HVOF contém incrustações de partículas abrasivas, oriundas das impurezas que não foram totalmente removidas da limpeza da peça antes da aplicação do revestimento. Dessa forma, é possível observar que não houve uma boa coalescência do revestimento ao substrato. Porém é importante ressaltar que não houve destacamento da camada. Contudo, algumas pesquisas apontam que é necessário fazer a pré camada com aspersão de alumínio, para que o revestimento de tungstênio consiga aderir com mais eficiência na peça em estudo.

Já para a microestrutura do cromo duro, foi possível observar microfissuras, que podem acelerar o processo de

Tabela 3. Resultados do ensaio de microdureza Vickers $H_{0.05}$

\begin{tabular}{cccc}
\hline Amostras/Liga & Dureza Média & Desvio Padrão & Dureza Média do Substrato \\
\hline FFN (substrato) & 342,3 & 90,1 & Desvio Padrão \\
Cr & 1100,4 & 300,9 & 329,6 \\
Wc & 1494,4 & 378,7 & 101,5 \\
\hline
\end{tabular}

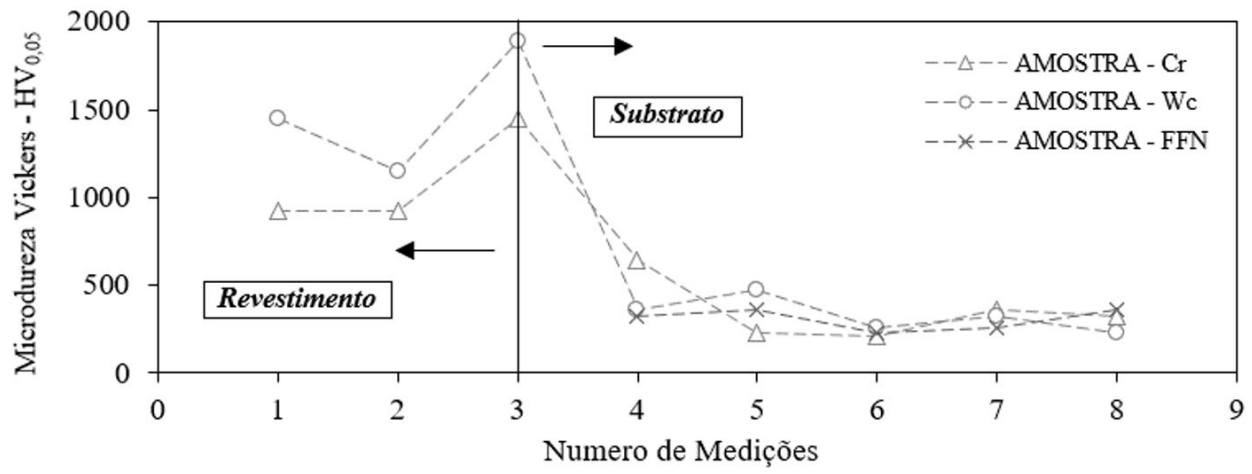

Figura 3. Perfil de microdureza Vickers $\mathrm{HV}_{0.05}$. 

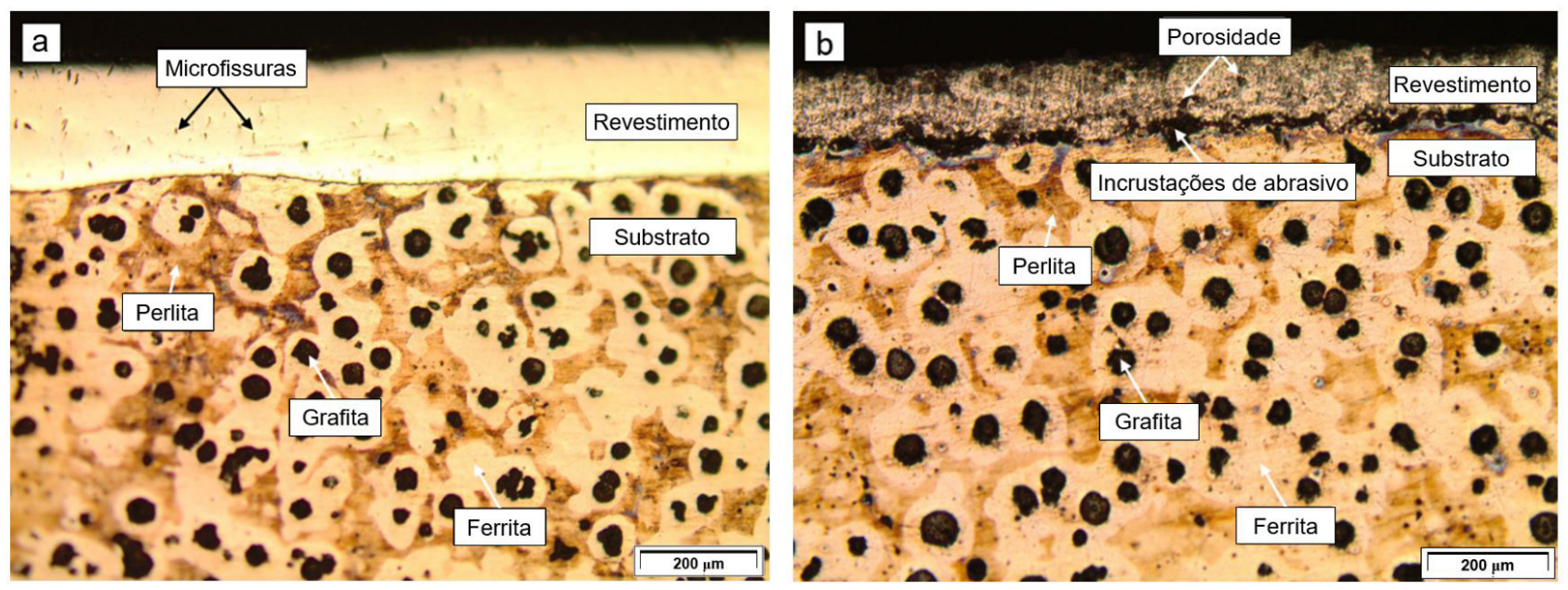

Figura 4. Micrografia dos revestimentos e substrato com ataque em nital $2 \%$ por 2 segundos. a) cromo duro e b) $\mathrm{Wc}-\mathrm{CoCr}$.

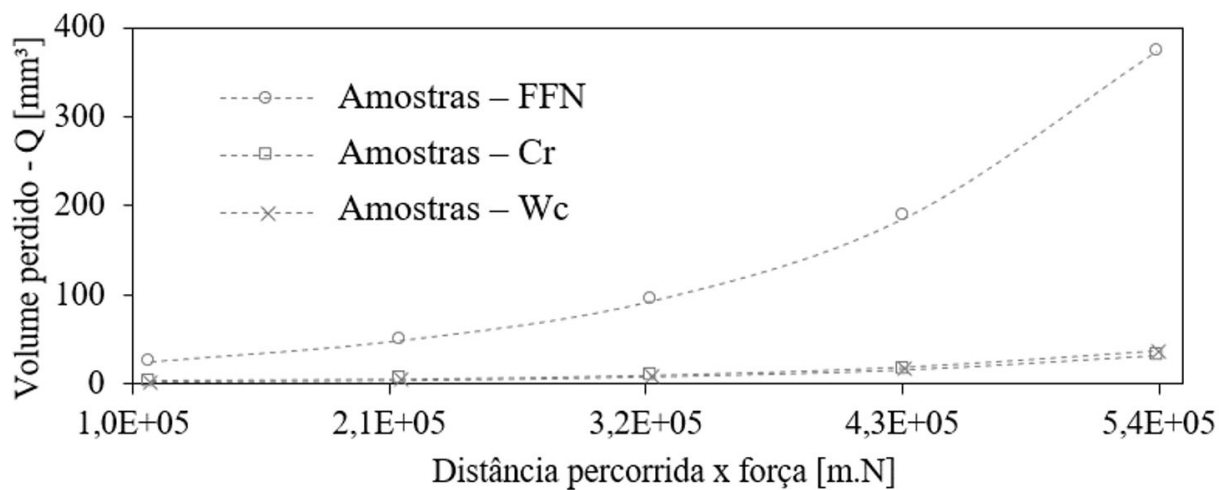

Figura 5. Análise da taxa de desgaste para as amostras.

oxidação no substrato e o início de um processo de lascamento do revestimento, assim prejudicando o seu desempenho no sistema tribológico [16]. Porém, observa-se que esse revestimento tem uma camada mais homogênea, e isso, influenciou levemente em uma menor taxa de desgaste, mesmo com uma menor microdureza encontrado dessa camada.

\subsection{Rugosidade dos corpos de prova}

Menezes, et al. [11], mostra que a rugosidade da superfície pode influenciar no desgaste abrasivo [11]. Portanto, foi necessário obter os valores de rugosidade média da superfície de cada corpo de prova na condição inicial, ou seja, antes do teste de roda de borracha. Com as 3 amostras para cada material, foi possível obter a média e o desvio padrão, sendo Ra de 6,59 $\pm 1,13 \mu \mathrm{m}$ para FFN, 9,12 $\pm 0,48 \mu \mathrm{m}$ para $\mathrm{Cr}$ e 7,76 $\pm 0,27 \mu \mathrm{m}$ para o WC. Preferiu-se não retificar as peças ensaiadas, pois melhor se assemelha à superfície da pá original, que estava com Ra de 8,5 $\pm 0,94 \mu \mathrm{m}$.

\subsection{Caracterização das argilas}

Na Tabela 4, apresentam-se os resultados obtidos das análises de FRX das argilas.

Através da Tabela 4 identifica-se que mais de $75 \%$ da composição da massa é composto por óxido de silício e de
Tabela 4. Principais compostos químicos da argila

\begin{tabular}{ccc}
\hline Compostos químicos & Cerâmica 1 (\%) & Cerâmica 2 (\%) \\
\hline $\mathrm{SiO}_{2}$ & 65,1 & 64,7 \\
$\mathrm{Al}_{2} \mathrm{O}_{3}$ & 24,0 & 22,6 \\
$\mathrm{Fe}_{2} \mathrm{O}_{3}$ & 6,2 & 6,1 \\
$\mathrm{~K}_{2} \mathrm{O}$ & 2,4 & 3,3 \\
\hline
\end{tabular}

alumínio, dois materiais extremamente abrasivos e prejudicial às peças mecânicas em deslizamento. Analisando apenas esta variável é possível esperar um desgaste maior na argila da cerâmica 1. De acordo com Macedo [17] a sílica $\left(\mathrm{SiO}_{2}\right)$ é um composto químico muito encontrado e com grandes proporções na composição destas massas [17]. Para verificar a ação abrasiva da sílica, foi necessário avaliar os compostos cristalinos de cada amostra. Nos resultados obtidos por DRX, mostrou que o componente cristalino mais abundante na amostra é o quartzo. Segundo Stoeterau e Leal [9] o quartzo tem uma dureza de $800 \mathrm{HV}$ [9].

\subsection{Ensaio de desgaste - ASTM G65}

A Tabela 5 apresenta a taxa e do coeficiente de desgaste $\left(K_{a}\right)$. Também a Figura 5 apresenta o volume perdido acumulado de cada material. 
Tabela 5. Resultados encontrados do ensaio de desgaste acelerado

\begin{tabular}{cccc}
\hline Amostras/Liga & Taxa de desgaste $\mathbf{Q} / \mathbf{L}\left(\mathbf{m m}^{\mathbf{3}} / \mathbf{m}\right)$ & Coeficiente de Desgaste $-\boldsymbol{K}_{a}$ & Estimativa de vida útil (horas) \\
\hline FFN & $0,0901 \pm 0,008$ & $7,727 \pm 0,701 \times 10^{-4}$ & $5,55 \mathrm{E}+06$ \\
Cr & $0,0076 \pm 0,001$ & $6,490 \pm 0,910 \times 10^{-5}$ & $6,58 \mathrm{E}+07$ \\
Wc & $0,0091 \pm 0,001$ & $7,680 \pm 0,846 \times 10^{-5}$ & $5,49 \mathrm{E}+07$ \\
\hline
\end{tabular}

Tabela 6. Resultados da aplicação prática dos revestimentos

\begin{tabular}{cccccc}
\hline Peças/Liga & Peso (g) 02/10/2018 & Peso (g) 14/11/2018 & Perda de Massa (g) & Identificação das argilas & $\begin{array}{c}\text { Granulometria das } \\
\text { argilas }(\boldsymbol{\mu m}) *\end{array}$ \\
\hline P2 - Wc & 3185,4 & 2890,2 & 295,2 & Cerâmica 1 & 12,54 \\
P3 - Cr & 3372,9 & 3283,0 & 89,9 & & \\
P5 - FFN & 3339,0 & 2725,5 & 613,5 & 4,80 \\
P1 - Wc & 3266,3 & 2711,6 & 554,7 & Cerâmica 2 & \\
P4 - Cr & 3322,8 & 3099,8 & 223,0 & & \\
P6 - FFN & 3212,2 & 2440,3 & 771,9 & & \\
\hline
\end{tabular}

*Tamanho médio das partículas de argila.

Com os resultados da Figura 5 e Tabela 5 pode-se observar que os revestimentos tiveram resultados semelhantes, porém o cromo duro obteve um melhor desempenho ao sistema tribológico em estudo, obtendo uma taxa de desgaste média de $0,0076 \mathrm{~mm}^{3} / \mathrm{m}$, e um ganho de aproximadamente 11 vezes mais em relação ao substrato sem revestimento (ferro fundido), que obteve uma taxa média de $0,0901 \mathrm{~mm}^{3} / \mathrm{m}$. De acordo com Achard [14] este sistema tribológico se enquadra em um regime moderado para severo, pois o maior coeficiente de desgaste encontrado é de $8,25 \times 10^{-5}$ [14]

\subsection{Teste de Aplicação Industrial}

Visto que a análise em laboratório obteve uma grande melhora no desgaste das superfícies revestidas, levou-se os testes para a área industrial, a fim de analisar mais precisamente e comparativamente as argilas em análise. Como o testes industriais foi realizada num tempo relativamente curto (43 dias), a análise foi feita apenas com um comparativo de perda de massa (g), medindo a massa das pás no início do testes e ao final da data de inspeção, conforme apresentado na Tabela 6 .

Com o ensaio prático real pode-se concluir que a argila da Cerâmica 1 obteve uma ação mais agressiva no componente mecânico testado, obtendo uma perda de massa maior que a argila da Cerâmica 2. Davim [15] e Hernandez [18] explicam, que pelo fato da sua porcentagem de sílica e granulometria ser maior, acaba desgastando mais as peças em estudo $[15,18]$. Porém é importante ressaltar que o revestimento de cromo duro teve o melhor desempenho nos dois casos.

\section{Conclusão}

A partir dos resultados obtidos nos estudos teóricos e experimentais, pode-se inferir algumas conclusões:

- Os dois revestimentos conseguiram melhorar a performance das pás dos misturadores. A taxa de desgaste encontrada nos revestimentos foi menor quando comparado ao ferro fundido nodular. Para o Cr teve um ganho de $91,52 \%$ na taxa de desgaste, já para o carboneto de tungstênio foi de $89,85 \%$.

- A partir dos resultados obtidos do coeficiente de desgaste, foi possível fazer também uma estimativa de vida útil dos revestimentos comparada ao FFN. Nesse estudo, obteve-se um tempo de vida de 10 e 12 vezes a mais com o $\mathrm{Wc}$ e o $\mathrm{Cr}$, respectivamente. Contudo, levando em consideração os valores comerciais por hora de cada revestimento aplicado nas pás, juntamente com o tempo de vida útil, percebeu-se que apenas o revestimento com cromo $(\mathrm{Cr})$, teve a viabilidade de aplicação. Ou seja, usando as pás fabricadas com FFN, o custo seria em torno de $5,51 \times 10^{6} \mathrm{R} \$ / \mathrm{h}$, e para as pás revestidas com $\mathrm{Cr}$ e Wc, seria de 2,16 x $10^{6} \mathrm{e}$ $5,75 \times 10^{6}$, respectivamente, inviabilizando a utilização do carboneto de tungstênio para esse estudo.

- Com as imagens microscópicas foi possível verificar que o carbeto de tungstênio não obteve um ancoramento adequado no substrato, podendo haver impurezas que não conseguiram ser retiradas na limpeza da peça. Também, é possível verificar a porosidade acentuada no revestimento, assim tornando a camada não homogênea;

- A maior microdureza média do revestimento pôde-se identificar no revestimento com carbeto de tungstênio, porém o cromo duro obteve um menor desgaste, devido a sua homogeneidade e ancoramento no substrato.

- Como a porcentagem de sílica é muito similar entre as duas argilas, o que mais agravou o aumento do desgaste na Cerâmica 1, possivelmente foi a granulometria da matéria prima e as pedras oriundas da jazida em sua composição.

- O método de aspersão térmica - HVOF para esta aplicação específica, levando em consideração os parâmetros de máquinas, preparação das superfícies, além do seu custo, tornou-se ainda inviável para a aplicação real. Mas, não se pode descartar esse método de deposição, principalmente porque existem outras ligas disponíveis contra o desgaste abrasivo e que podem ser mais atrativas economicamente. 


\section{Referências}

1 Rojas E, Vergara V, Soto R. Case study: Discrete element modeling of wear in mining hoppers. Wear. 2019;430431:120-125.

2 Holmberg K, Kivikyto-Reponen P, Harkisaari P, Valtonen K, Erdemir A. Global energy consumption due to friction and wear in the mining industry. Tribology International. 2017;115:116-139.

3 Sales JC, Morais JEV, Sancho EO, Ferreira AC, Nascimento JPC, Castro AJN, et al. As argilas para fabricar cerâmica vermelha no nordeste brasileiro. In: Anais do $60^{\circ}$ Congresso Brasileiro de Cerâmica; 201615 a 18 de maio; Águas de Lindóia, Brasil. São Paulo; 2016. p. 601-612.

4 Klein AN, Binder C, Binder R, Klein AN. Effect of nature of nitride phases on microabrasion of plasma nitrided sintered iron. Tribology. 2010;4(4):191-196.

5 NATREB. [página da internet]. Misturador MTR-4B. [acesso em 07 abr. 2019]. Disponivel em: https://natreb.com.br

6 Santos IMG, Silva JM, Trindade MFS, Soledade LEB, Souza AG, Paskocimas CA, et al. Efeito da adição de rejeito na redução de coração negro em cerâmicas vermelhas. Cerâmica 51. 2005;51:144-150.

7 Goettems FS, Ferreira JZ. Influência do Tratamento Térmico na Resistência ao Desgaste de Revestimentos de Níquel Químico com Alto Teor de Fósforo. Tecnologica em Metalurgia, Materiais e Mineração. 2018;14(3):264-272.

8 Mendes RBA. Efeito do tecimento triangular e trapezoidal sobre revestimentos aplicado com arames tubulares quanto à resistência ao desgaste abrasivo. Natal: Universidade Federal do Rio Grande do Norte; 2018.

9 Stoeterau RL, Leal LC. Tribologia - Apostila de Graduação. Florianópolis: Universidade Federal de Santa Catarina - UFSC; Departamento de Engenharia Mecância; 2004. p. 110-180.

10 Kayaba T, Iwabuchi A. Effect of the hardness of hardened steels and the action of oxides on fretting wear. Wear. 2014;(66):27-41.

11 Menezes PL, Ingole SP, Nosonovsky M, Kailas SV, Lovell MR. Tribology for Scientists and Engineers. New York: Springer; 2013. p. 233-268.

12 Mate CM, Carpick RW. Tribology on the small scale: a modern textbook on friction, lubrication, and wear. USA: Oxford University Press; 2019.

13 ASTM International. ASTM G65-16, Standard Test Method for Measuring Abrasion Using the Dry Sand/Rubber Wheel Apparatus, West Conshohocken: ASTAM; 2016.

14 Archard JF. Contact and rubbing of flat surface. Journal of Applied Physics. 1953;24:981-988.

15 Davim JP. Tribology in Manufacturing Technology. Springer, Berlin Heidelberg, 2013.

16. Castro RM, Rocha AS, Mercado Curi EI, Peruch F. A comparison of microstructural, mechanical and tribological properties of WC-10Co4Cr-HVOF coating and hard chrome to use in hydraulic cylinders. American Journal of Materials Science. 2018;8(1):15-26.

17 Macedo RS, Menezes RR, Neves GA, Ferreira HC. Estudo de argilas usadas em cerâmica vermelha. São Paulo: Cerâmica 54; 2008. (Vol. 54; p. 411-417).

18 Hernandez OS. Otimização do consumível na solda de revestimento aplicada na indústria sucroalcooleira [dissertação]. São Carlos, SP: UFSCar, DEMa, P.P.G.; 1997. 102 p.

Recebido em: 23 Nov. 2019

Aceito em: 16 Jun. 2020 